$N$

Global Journals In

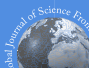

\title{
Nitrogen Sorption Isotherms of Biologically Synthesized Non- Stoichiometric Hydroxyapatite Nanoparticles (HAp NPs) Extracted from Fish Bones
}

By Mohamad Rais Hasan, Mohd Sabri Mohd Ghazali \& Nor Fazliyana Mohtar University Malaysia Terengganu

Abstract- Hydroxyapatite (HAp) with the chemical formula of $\mathrm{Ca}_{10}\left(\mathrm{PO}_{4}\right)_{6}(\mathrm{OH})_{2}$ is a mineral component found in bone structure, and has broad application in many fields. Several sources can be used for the extraction of HAp either synthetic or natural. However, sources such as porcine and bovine have drawbacks that decreased the demand of HAp.This study aimed toextract and determine particle size distribution and pore characteristics ofhydroxyapatite nanoparticles (HAp NPs) derived from spotted sardinella (Amblygaster sirm). Further characterization of extracted HAp NPswas carried out by Scanning Electron Microscopy (SEM), Energy Dispersive X-ray Spectroscopy (EDS)and Brunauer-Emmett-Teller(BET).SEM analysis has shown that the extracted HApNPs has an irregular sphere-like shape with particle size distribution ranged from $95 \mathrm{~nm}$ to $100 \mathrm{~nm}$.

Keywords: HAp NPs, nitrogen sorption, fish bone, characterization, non-stoichiometric.

GJSFR-C Classification: FOR Code: 279999

Strictly as per the compliance and regulations of:

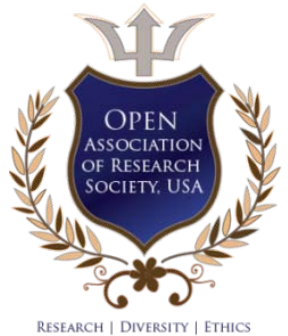

(C) 2021. Mohamad Rais Hasan, Mohd Sabri Mohd Ghazali \& Nor Fazliyana Mohtar. This is a research/review paper, distributed under the terms of the Creative Commons Attribution-Noncommercial 3.0 Unported License http://creativecommons.org/ licenses/by-nc/3.0/), permitting all non commercial use, distribution, and reproduction in any medium, provided the original work is properly cited. 


\title{
Nitrogen Sorption Isotherms of Biologically Synthesized Non-Stoichiometric Hydroxyapatite Nanoparticles (HAp NPs) Extracted from Fish Bones
}

\author{
Mohamad Rais Hasan ${ }^{\alpha}$, Mohd Sabri Mohd Ghazali ${ }^{\circ}$ \& Nor Fazliyana Mohtar ${ }^{\rho}$
}

Abstract- Hydroxyapatite (HAp) with the chemical formula of $\mathrm{Ca}_{10}\left(\mathrm{PO}_{4}\right)_{6}(\mathrm{OH})_{2}$ is a mineral component found in bone structure, and has broad application in many fields. Several sources can be used for the extraction of HAp either synthetic or natural. However, sources such as porcine and bovine have drawbacks that decreased the demand of HAp.This study aimed toextract and determine particle size distribution and pore characteristics ofhydroxyapatite nanoparticles (HAp NPs) derived from spotted sardinella (Amblygaster sirm). Further characterization of extracted HAp NPswas carried out by Scanning Electron Microscopy (SEM), Energy Dispersive X-ray Spectroscopy (EDS)and Brunauer-Emmett-Teller(BET).SEM analysis has shown that the extracted HApNPs has an irregular sphere-like shape with particle size distribution ranged from $95 \mathrm{~nm}$ to $100 \mathrm{~nm}$. The EDS analysis confirmed the presence of calcium $(\mathrm{Ca})$, phosphorus $(\mathrm{P})$ in the extracted nano-HAp and the $\mathrm{Ca} / \mathrm{P}$ ratio was 1.64 , which is acceptable for HApnon-stoichiometric molar ratio. Nitrogen sorption analysis demonstrated that the extracted HAp NPs has high specific surface area and pore volume which was $22.07 \mathrm{~m}^{2} / \mathrm{g}$ and $0.1179 \mathrm{~cm}^{3} / \mathrm{g}$, respectively. HAp NPs demonstrated similar properties to the standard HAp and possessed excellent physico-chemical properties due to the nanoparticle size that contribute to the large specific surface area. Overall findings have demostrated that the extracted HAp NPs from spotted sardinella bone had successfully produce nonstoichiometric HAp NPs with a large specific surface area. Such characteristics is important for HAp NPs that differed itself from conventional-sized HAp. This study suggested that the synthesized HAp NPs could be potentially used as an alternative materials for various applications.

Keywords: HAp NPs, nitrogen sorption, fish bone, characterization, non-stoichiometric.

\section{INTRODUCTION}

B one is a combination of organic and inorganic components that provides mechanical strength and stability to the structure (Dorozhkin, 2013). The organic components include fat, collagenous, and non-collagenous proteinthat are packed together with inorganic nano-hydroxyapatite (nano-HAp) to form a

Author a $\rho$ : Faculty of Fisheries and Food Science, Universiti Malaysia Terengganu, 21030, Kuala Nerus, Terengganu, Malaysia.

e-mail: fazliyana@umt.edu.my

Author 6: Faculty of Science and Marine Environment, Universiti Malaysia Terengganu, 21030, Kuala Nerus, Terengganu, Malaysia. bone structure(Poinern et al., 2016). Nano-Hap with achemical formula of $\mathrm{Ca}_{10}\left(\mathrm{PO}_{4}\right)_{6}(\mathrm{OH})_{2}$ is an organic mineral component found in bone and teeth which possesses excellent biological properties (Barakat et al., 2009; Jahan et al., 2017). It has exceptional biocompatibility due to their similar structure and composition with boneand enamel of teeth (Dorozhkin, 2013; Tsai et al., 2008; Zhou and Lee, 2011). Nano-Hap constitutes in bone and enamel structure of teeth usually in rod-like shaped nano-crystal with an average size of 20 to 50nm(Ajami et al., 2016).

Nano-HAp has many applications in medical, pharmaceutical, and dentistry due to its enhanced biocompatibility, bioactivity, non-inflammatory behavior, non-immunogenicity and high osteoconductive properties (Giraldo-Betancur et al., 2013; Huang and Chu, 2013). Nano-HAp has the capability to assist the growth of new bone and enhanced the bone structure due to its osteoconductivity without any inflammatory effects (Sobczak-kupiec et al., 2018). The application of nano-HAp as a scaffold in generating a new bone depending on the optimum condition of its porosity and pore size (Ofudje et al., 2018). Nano-Hap can be used in the medical field as an alternative coating material to increase theattachment strength of bone to metalimplants(Coatchup et al., 1999). It also has the potential to be applied in dentistry field for regenerating the enamel layers of damaged teeth(Zhou and Lee, 2011). Nano-Hap fulfilled the required criteria to be applied in most medical and dentistry purposes related to living things due to its excellent biocompatibility.

However, the morphological structure and size of nano-HAp influence the mechanical properties and biological behavior of the particles. Different size of nano-HAp has different application due to its different properties. The composition, crystallinity, morphology, and particle size of nano-HAp are the essential characteristics which affect its performance and utilization (Jahan et al., 2017, Sun et al., 2017).

The properties of nano-HAp are also influenced by the source and methods of extraction process (Sun et al., 2017). The extraction process of nano-HAp consists of natural and synthetic methods. Nano-HAp 
can be produced syntheticallyfrom chemical such as wet chemical precipitation Fernando et al., 2015; Gentile et al., 2015; Kamieniak et al., 2016; Nazari et al., 2014; Zanotto et al., 2012), sol-gel (Agrawal et al., 2011), spray drying (Chow and Hockey, 2004; Ruphuy et al., 2016), hydrothermal transformation (Hu et al., 2001; Sivaperumal and Mani, 2017). Meanwhile, natural approach involve heat treatment of bone such as bovine bone (Barakat et al., 2009, Bahrololoom et al., 2009; H|Khoo et al., 2015; Gentile et al., 2015), fishbone (Boutinguiza et al., 2012; Ozawa et al., 2007; Venkatesan et al., 2015; Pal et al., 2017), fish scale (Huang and Chu, 2013; Prasad et al., 2017), eggs shell (Gergely et al., 2010; Khandelwal and Prakash, 2016; Rivera et al., 1999), and snail shell (Adak and Purohit, 2011).This method is preferred over the synthetic method due to its low-cost, time-saving and simple procedure (Sun et al., 2017).

There are a few studies have been reported on the extraction of nano-HAp from natural sources for different field of applications. In this paper, the preparation of natural nano-HAp has been extracted from spotted sardinella (Amblygastersirm) bone using heat treatment. The fish bone was obtained from fish processing industries which in return will help to reduce the environmental pollution by promoting the potential use of the fish by-products. Therefore, this study aimed to extract and characterize the elemental composition and pore characteristics from nitrogen $\left(\mathrm{N}_{2}\right)$ isotherms of nano-HAp from A.sirm bone and compare with standard. The extraction was carried out at different calcinations temperatures of $600^{\circ} \mathrm{C}, 700^{\circ} \mathrm{C}, 800^{\circ} \mathrm{C}$, $900^{\circ} \mathrm{C}$ and $1000^{\circ} \mathrm{C}$. The nano-Hap particles were characterized using Scanning Electron Microscope (SEM) equipped with EDAX and Micromeritics devices.

\section{il. Materials and Methods}

\section{a) Preparation of raw material}

A total amount of $50 \mathrm{~kg}$ of spotted sardinella (Amblygastersirm) bone was collected from local fish processing industry and stored in a freezer at $-20^{\circ} \mathrm{C}$. Standard hydroxyapatite(HAp) was purchased from Sigma and used as control. The frozen raw material proceeded to bone separation process and boiled before it was then rinsed with tap water to remove adherent fish meat. The raw material was dried in an oven.

\section{b) Extraction of nano-hydroxyapatite}

The extraction of nano-hydroxyapatite (nanoHAp) was carried out according to the method of Boutinguiza et al., (2012).The dried bone was heated in a furnace(Carbolite, UK) at different temperature and it was cooled isothermally in dessicator. The calcined bone was milled for using the ball-mill(Retsch PM 100, Germany).

\section{c) Scanning Electron Microscopy}

Scanning Electron Microscopy (SEM) analysis was carried out according to the method of Boutinguiza et al., (2012). The morphology of nano-Hap was determined by a Scanning Electron Microscope(JEOL JSM-6360LA, Japan) and (JEOL JSM-6610LV, Japan). The nano-HAp were coated with a thin gold layer before observed under a microscope.

\section{d) Energy Disperse Spectroscopy}

Energy Disperse Spectroscopy (EDS)analysis was carried out according to the method of Boutinguiza et al., (2012). The composition of nano-Hap was determined by a Scanning Electron Microscope (JEOL JSM-6360LA, Japan)equipped with an EDAX detector for energy dispersive microanalysis (EDX) to analyze local chemical composition.

\section{e) Nitrogen sorption analysis}

Pore parameters analysis was carried out based on Bruaauer-Emmett-Teller (BET) theorem followed to the method from Ciobanu et al., (2011)using Micromeritics (ASAP 2020, USA).Thepore parameters such as pore size $(\mu \mathrm{m})$, pore volume $\left(\mathrm{cm}^{3} / \mathrm{g}\right)$ and BET surface area $\left(\mathrm{m}^{2} / \mathrm{g}\right)$ were calculated from the adsorption branch of isotherms based onBarrett-Joyner-Halenda (BJH).

\section{f) Statistical analysis}

Analysis of Variance (one way ANOVA) and multiple comparisons (Posthoc test) was applied in this study. Comparisons of changes in $\mathrm{Ca} / \mathrm{P}$ and pore parameters were performed to determine the significant. The level of significance was set at $\alpha=0.05$. Statistical analyses were performed using SPSS for Windows (version 23.0).

\section{ili. Results and Discussion}

\section{a) Morphological structure and particle size distribution}

SEM analysis was performed to observe the morphological composition and particle size distribution of raw bone (RB), extracted hydroxyapatite nanoparticles (HAp-1) compared to the standard hydroxyapatite (HAp-2). The SEM images and particle size distribution of RB, HAp-1 and HAp-2 are presented in Figure 1. All of the SEM images show the particle structure on the surface of the powders. The morphological structure of raw bone (RB) showed an amorphous shape and size consisting of decomposed inorganic materials and the small size of the hydroxyapatite (HAp) particle. This phenomenon could be due to the composition of inorganic materials contained in the RB, including HAp particle that has a particle size distribution ranging from 90 to $100 \mu \mathrm{m}$. The particle size of RB seems to have larger particle structure compared to the HAp-1 and HAp-2 due to the packed structure of particles with a combination of inorganic materials such as collagen proteins and HAp 
crystals. This finding is further supported by Sutapaet al., (2016) who stated that the raw bone consists of inorganic materials including collagens, fats, proteins and mineral compounds which decomposed after the calcination process except for HAp.
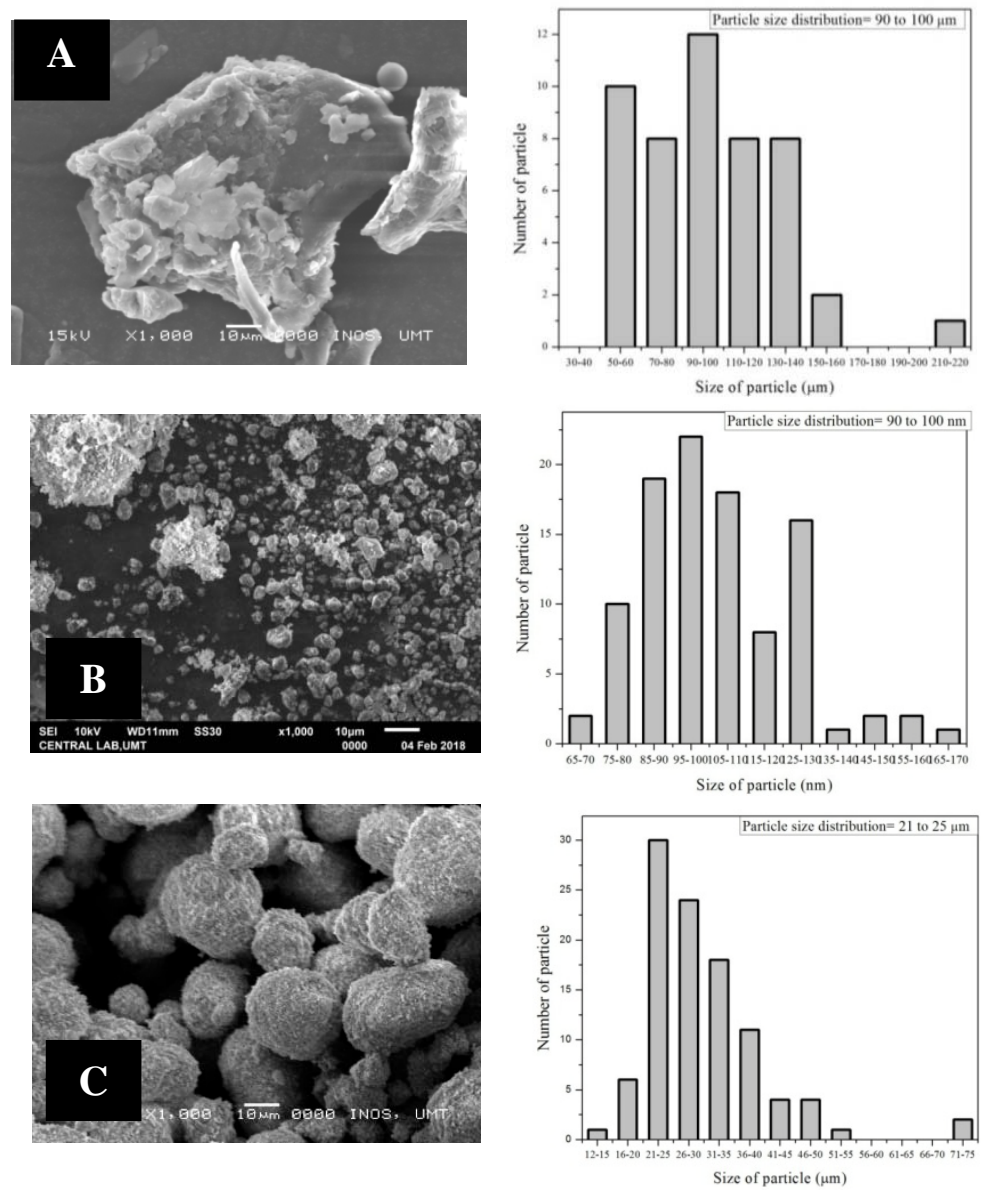

Figure 1: SEM images and particle size distribution of RB (A), HAp-1 (B) and HAp-2 (C). Magnification: X1000, Volt : $15 \mathrm{kv}, 10 \mathrm{kv}$.

${ }^{*}$ RB represents: Raw bone

*HAp-1 represents: Extracted nano-hydroxyapatite

*HAp-2 represents: Standard hydroxyapatite

There were slight differences in the morphological structure of HAp-1. It exhibited smaller particles compared to the ones observed for RB and HAp-2. These HAp particles consisted of irregular and agglomerated sphere-like shapes with particle size distribution ranging from 95 to $100 \mathrm{~nm}$. The morphological structure of HAp-1 was found to be agglomerated, consisting of tiny crystal particles. The spherical morphology and agglomerated structure of HAp-1 are similar to the particle morphology reported by Poinern et al., (2016). This phenomenon may be due to the effect of the milling process and also was influenced by the calcination temperature. The calcination temperature used in the present study was $700^{\circ} \mathrm{C}$ and this has changed the particle size of HAp-1, leading to the formation of the agglomerated nano-sized particles after the milling process (Sofronia et al., 2014). The

calcination temperature has altered the size and shape of the HAp-1 particles with high agglomeration due to the low temperature used (Guo et al., 2013). The finding of the present study is supported by Sun et al., (2017) who found a similar finding on the structure of calcinedHAp which has an irregular shape with a particle size ranging from 20 to $100 \mu \mathrm{m}$. This finding is further supported by Sofronia et al., (2014). who found similar findings on the morphological structure of HAp-1 which had pseudo-spherical shape particles consisting of a large agglomerated structure with sizes less than 955 $\mathrm{nm}$. The nano-sized HAp was previously reported to have an elongated shape with a particle size of less than $100 \mathrm{~nm}$ (Jahan et al., 2017).

The HAp-2 exhibited a larger particle size with fixed shape when compared to those The HAp-2 exhibited a larger particle size with fixed shape when 
compared to those observed for RB and HAp-1. The Hap-2 consisted of the spherical shape of the HAp particle with a particle size distribution ranging from 21 to $25 \mu \mathrm{m}$. The particle size of HAp-2 seems to have larger particle structure compared to the HAp-1 sample due to the high crystallinity and growth of the HAp crystal particles. The increasing of calcination temperature influenced the grain growth and crystallization of HAp particles due to the absorption of heat energy during synthesis process (Guo et al., 2013; Khoo et al., 2015). The present finding is further supported by Sun et al., (2017) who found similar conclusions on the morphological structure formed by the standard HAp particle which has a spherical shape with a size range of 5 to $15 \mu \mathrm{m}$. A summary of findings on the morphological structure and particle size distribution of HAp from various studies is shown in Table 1. It can be seen that the morphological structures of HAp consist of various shapes, depending on the source of extraction. It also influences the particle size distribution of HAp.

Table 1: Various findings of morphological structures and particle size distributions of HAp extracted from different sources

\begin{tabular}{llcl}
\hline \multicolumn{1}{c}{ Sample } & \multicolumn{1}{c}{$\begin{array}{c}\text { Morphological } \\
\text { structure }\end{array}$} & $\begin{array}{c}\text { Particle size } \\
\text { distribution }(\mu \mathrm{m})\end{array}$ & \multicolumn{1}{c}{ Reference } \\
\hline Tuna bone & Irregular crystal-like & $5-10$ & Sutapa et al., (20160 \\
& structure & & Barakat et al., (2009) \\
Bovine bone & Nano rod-like structure & 0.3 & Ozawa et al., (2007) \\
Seabass bone & Crystalline aggregates & 0.2 & Pal et al., (2017) \\
Sea bass bone & Irregular structure & $0.005-0.055$ & Muhammad et al., (2016) \\
Carp fish scale & Crystal-like structure & 0.1 & Sun et al., (2017) \\
Bovine bone & Irregular & $20-100$ & Khoo et al., (2015) \\
Bovine & Irregular & 45 & \\
\hline
\end{tabular}

The size of HAp-1 was in the range of nanoparticles size and with an inconsistent shape. The production of HAp from biological sources commonly exhibited slight inconsistencies in shape and size. This phenomenon is related to the composition, properties of the bone and effect of the milling process that contributed to the shape and size of the HAp particles. Venkatesan et al., (2015) stated that the morphological characteristic of HAp extracted from salmon fish bone was in agglomerated and irregular particles. The finding of the present study is further supported by Sunil and Jagannatham (2016). who found that the SEM images of HAp extracted from roholabio fish bone exhibited large agglomerated particles. Other researchers (Coelho et al., (2007); Corrêa and Holanda, (2019); Mondal et al., (2012); also reported that the SEM images of HAp nanostructure extracted from fish bone demonstrated agglomerated and irregular particles. A comparison of SEM images of this study of the structure of fish bone HAp with previous studies demonstrated similar agglomerated and inconsistent HAp particles with variations in particle size distribution. This finding is also in a good agreement with the result in Section 3.5, which demonstrated that the specific surface area ofHAp-1 was higher than the other samples. The correlation of the size of the particles with the surface area was inversely proportional. Generally, the surface area of nanoparticles (NPs) isrelatively large due to presence of many reactive areas on the particle structure Christian et al., (2008). The shape and size of HAp particle is important to this study due to the primary characteristics of an abrasive material in toothpaste formulation.

\section{b) Transition phase}

Energy Dispersive X-ray Spectroscopy (EDS) analysis was conducted mainly to confirm the calciumto-phosphorus $(\mathrm{Ca} / \mathrm{P})$ ratio of raw bone $(\mathrm{RB})$, extracted hydroxyapatite nanoparticles (HAp-1) and standard hydroxyapatite (HAp-2) and its elemental composition. The $\mathrm{Ca} / \mathrm{P}$ ratio determination is compulsory data for supporting the transition phase for the formation of hydroxyapatite (HAp). There are several types of calcium phosphate-based materials such as HAp, betatricalcium phosphate (B-TCP), tetratricalcium phosphate (TTCP) and alpha-tricalcium phosphate $(\alpha-T C P)$. These materials can be generally distinguished by the $\mathrm{Ca} / \mathrm{P}$ molar ratio through EDS analysis. The transition phase of the materials is inconsistent depending on the source of extraction and temperature.

\section{c) Elemental composition}

The elemental composition of hydroxyapatite (HAp) is an important analysis to determine the major and other possible minor elements. Figure 2 shows the elemental contents of RB, extracted HAp-1 and HAp-2. The elemental composition of RB and HAp-1 contained abundant of elements compared to HAp-2. 


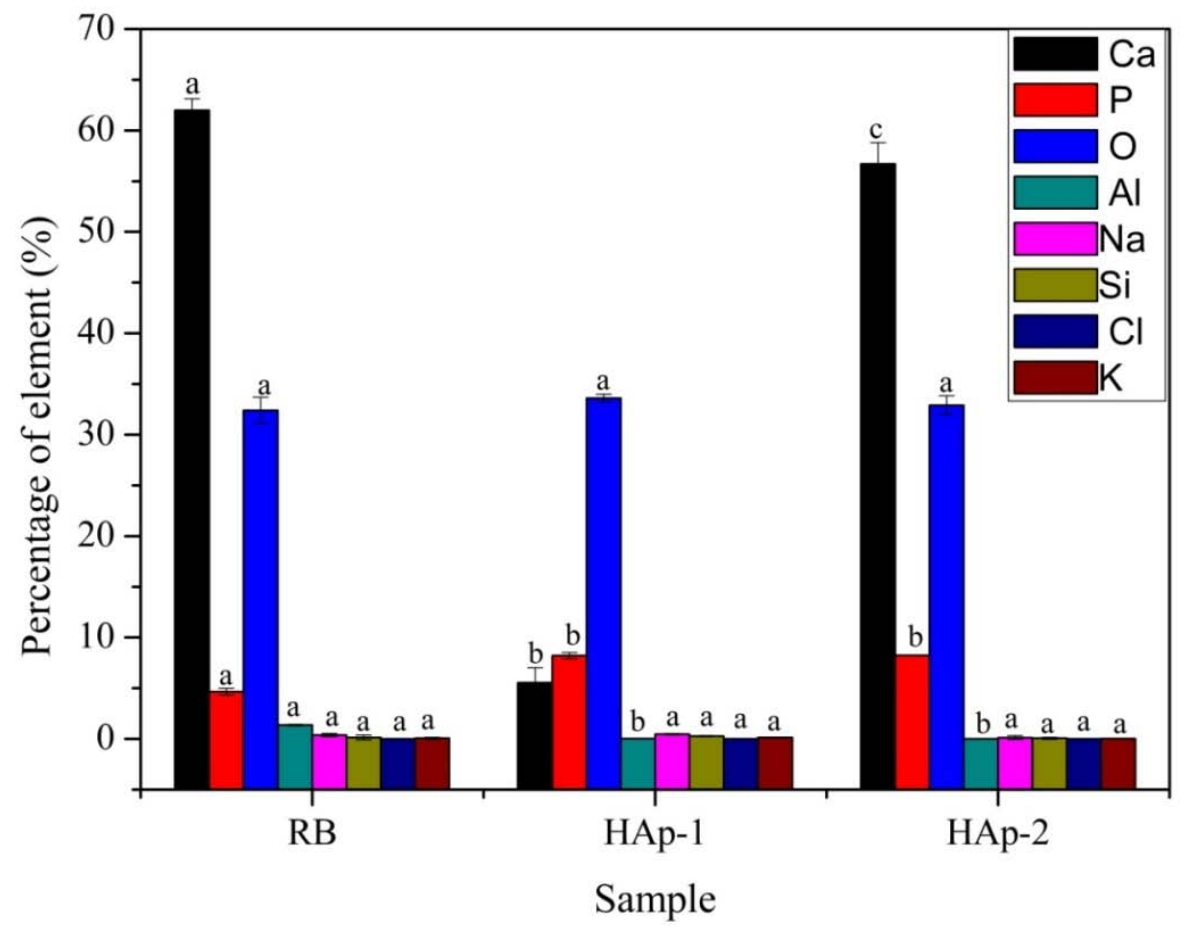

Figure 2: Comparison of percentage of elements of RB, HAp-1 and HAp-2

*Values are given as mean \pm SD for triplicate determinations.

*Values with the same superscript letters were not significantly different $(p<0.05)$.

RB: Raw bone; HAp-1: Extracted hydroxyapatite nanoparticles;

HAp-2: Standard hydroxyapatite

This phenomenon could be owing to the inheritance of mineral partly from the bone, which contains high amount of calcium and other trace elements such as aluminium (Al), sodium ( $\mathrm{Na}$ ), silicon (Si), chlorine $(\mathrm{Cl})$ and potassium $(\mathrm{K})$. HAp-2 contained fewer trace elements compared to RB and HAp-1 due to the chemically synthesized process which lacked of trace elements. This finding is further supported by another similar finding by Giraldo-Betancur et al., (2013) who demonstrated that the HAp possessed a high amount of other trace element and minerals that originated from the bone compared to the chemically synthesized HAp.

\section{d) Calcium to phosphorus ratio}

Based on the chemical formula of the hydroxyapatite (HAp), the theoretical stoichiometric calcium-to-phosphorus (Ca/P) ratio was 1.67 (Michael, et al., 2016). Figure 3 shows the $\mathrm{Ca} / \mathrm{P}$ ratio of raw bone (RB), extracted hydroxyapatite nanoparticles (HAp-1) and standard hydroxyapatite (HAp-2). The $\mathrm{Ca} / \mathrm{P}$ ratio of HAp is a vital characteristic which confirms the purity of the extracted HAp. It is related to the ionic interchange of HAp structure and other minor calcium phases, including calcium oxide, calcium carbonate and calcium hydroxide Giraldo-Betancur et al., (2013). The result showed that the $\mathrm{Ca} / \mathrm{P}$ ratio of $\mathrm{RB}, \mathrm{HAp}-1$ and HAp-2 were $3.18,1.64$ and 1.64 , respectively. The $\mathrm{Ca} / \mathrm{P}$ ratio of RB had a slightly higher value compared to HAp-1 and HAp-2. This phenomenon could be due to the nonstoichiometric ratio and variation of the element in the raw bone which influenced the ratio. The $\mathrm{Ca} / \mathrm{P}$ ratio of HAp-1 and HAp-2 exhibited a lower value than the theoretical stoichiometric ratio of HAp. 


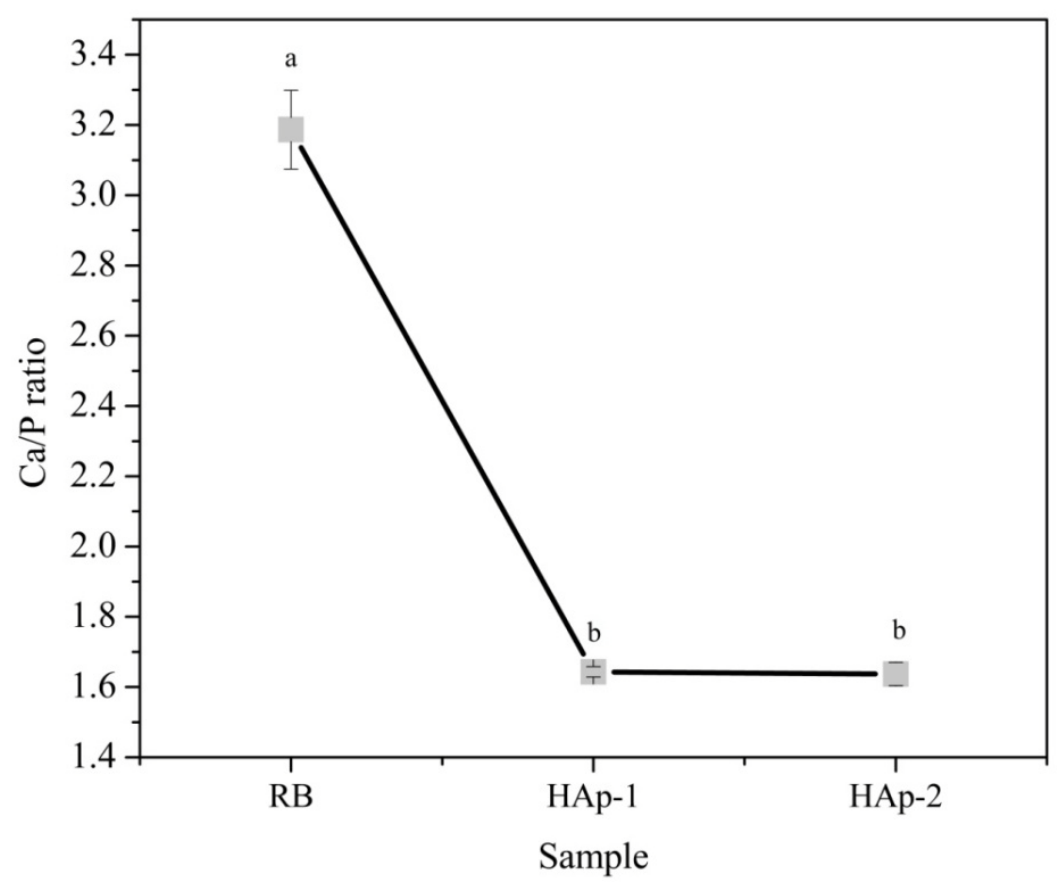

Figure 3: Comparison of $\mathrm{Ca} / \mathrm{P}$ ratio of RB, HAp-1 and HAp-2 for the confirmation of HAp.

*Values are given as mean \pm SD for triplicate determinations.

*Values with the same superscript letters were not significantly different $(p<0.05)$.

RB: Raw bone; HAp-1: Extracted hydroxyapatite nanoparticles;

HAp-2: Standard hydroxyapatite; HAp: Hydroxyapatite

However, it is an acceptable range for the HAp stoichiometric molar ratio, which ranged from 1.56 to 1.86 (Barakat et al., 2009). This finding is further supported by Michael, et al., (2016). who stated that the extracted HAp at different conditions showed high $\mathrm{Ca} / \mathrm{P}$ ratios which were $1.74,1.81$ and 1.87 . The $\mathrm{Ca} / \mathrm{P}$ ratio of HAp-1 in the present study is in a good agreement with those previously stated in Section 4.6.1 which demonstrated a high percentage composition of calcium $(\mathrm{Ca})$ and phosphorus $(\mathrm{P})$. The percentage composition of these elements varied depending on the source of extraction and temperature, thus determining the transition phase of the calcium phosphate-based material. The finding on $\mathrm{Ca} / \mathrm{P}$ ratio (1.64) of $\mathrm{HAp}-1$ indicated that the ratio was in the range of nonstoichiometric ratio for the formation of HAp. Therefore, the result indicated that the extracted HAp-1 was in the transition phase for non-stoichiometric HAp through the $\mathrm{Ca} / \mathrm{P}$ molar ratio determination.

e) Pore parameters and specific surface area

Nitrogen $\left(\mathrm{N}_{2}\right)$ adsorption and desorption analysis were carried out to analyze the pore parameter and specific surface area of raw bone (RB), extracted hydroxyapatite nanoparticles (HAp-1) and standard hydroxyapatite (HAp-2) based on the Brunauer-EmmettTeller (BET) theorem. The pore parameters and the specific surface area of the samples were evaluated from the adsorption-desorption branch of $\mathrm{N}_{2}$ isotherm (Figure 4) according to the Barrett-Joyner-Halenda (BJH) model. 


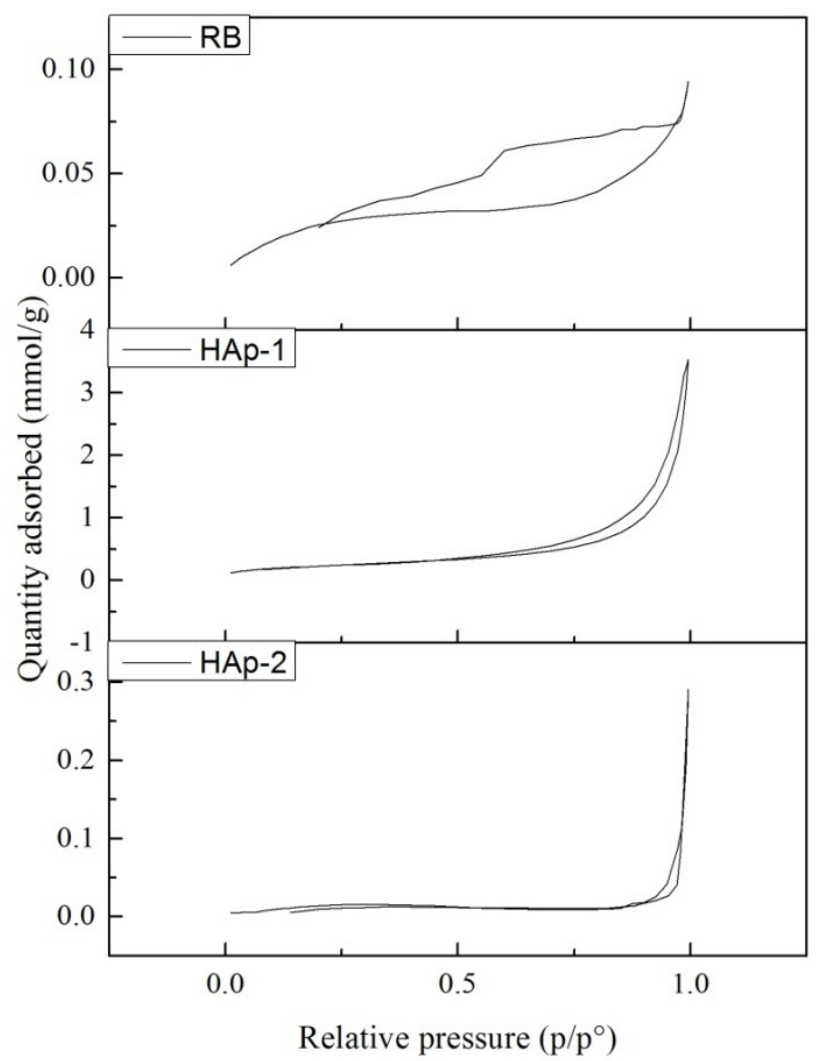

RB: Raw bone; HAp-1: Extracted hydroxyapatite nanoparticles;

\section{HAp-2: Standard hydroxyapatite}

The result demonstrated that all samples were identified as type I $N_{2}$ isotherms based on the International Union of Pure and Applied Chemistry (IUPAC) classification(IUPAC). However, extracted hydroxyapatite nanoparticles (HAp-1) demonstrated higher hysteresis loops at $\mathrm{P} / \mathrm{Po}>0.8$ due to their higher surface area compared to standard hydroxyapatite (HAp-2) and raw bone (RB). This phenomenon is closely related to the adsorption of $\mathrm{N}_{2}$ in the pore structure of the particles which determined the pore characteristics. The differences in adsorption isotherms might due to the different pore volume, specific surface area and pore size of the particles.

The shape of the RB, HAp-1 and HAp-2 corresponded to the type I heterosis loop which appeared to be a long hexagonal pore structure. This finding is in alignment with the basic hexagonal shape of hydroxyapatite (HAp) crystal which was made up of calcium $(\mathrm{Ca})$, phosphorus $(\mathrm{P})$, oxygen $(\mathrm{O})$ and hydrogen $(\mathrm{H})$ atoms as shown by Figure 6 . The arrangement of HAp crystal is usually in polycrystalline form which is slightly spaced between the crystals. The HAp obtained from biological sources commonly possesses polycrystalline crystals which differ depending on the source of HAp. The shape of HAp particles obtained from biological sources is usually irregularly shaped due to the simple form of extraction. In contrast, HAp obtained from synthetic sources has a fixed shape and the arrangement of the crystal is commonly crystalline. However, these synthetic sources usually require a higher cost, time-consuming and more complicated compared to biological sources. The differences in adsorption isotherms might due to the different specific surface area, pore volume and pore size of the particles. 

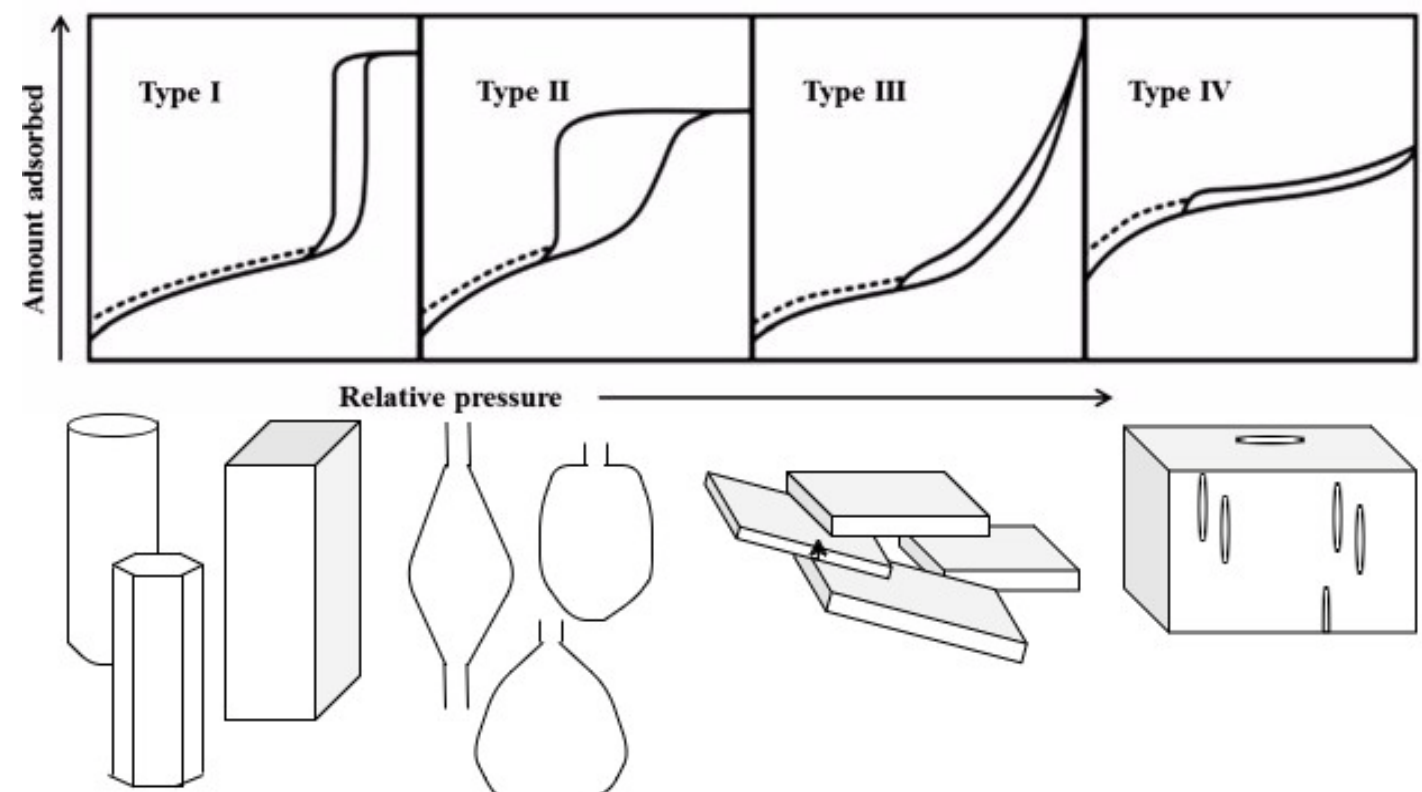

Relative pressure

Both ends

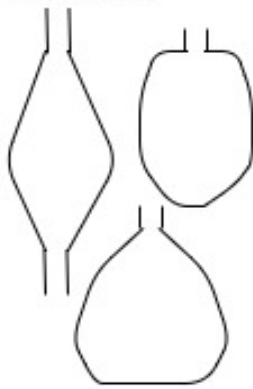

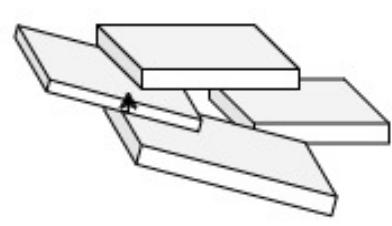

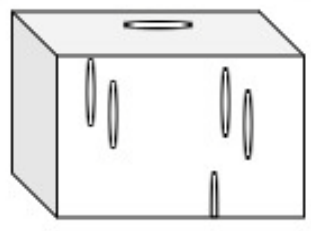

Slit-shaped
pore
Narrow-slit-

like pore

Figure 5: Pore structure characteristics based on $\mathrm{N}_{2}$ sorption

The shape of the RB, HAp-1 and HAp-2 corresponded to the type 1 heterosis loop which appear to be a long hexagonal pore structure. This finding was in alignment with the basic hexagonal shape of HAp crystal which made up of calcium (Ca), phosphorus (P), Oxygen $(\mathrm{O})$ and Hydrogen $(\mathrm{H})$ atoms as shown by Figure 6.
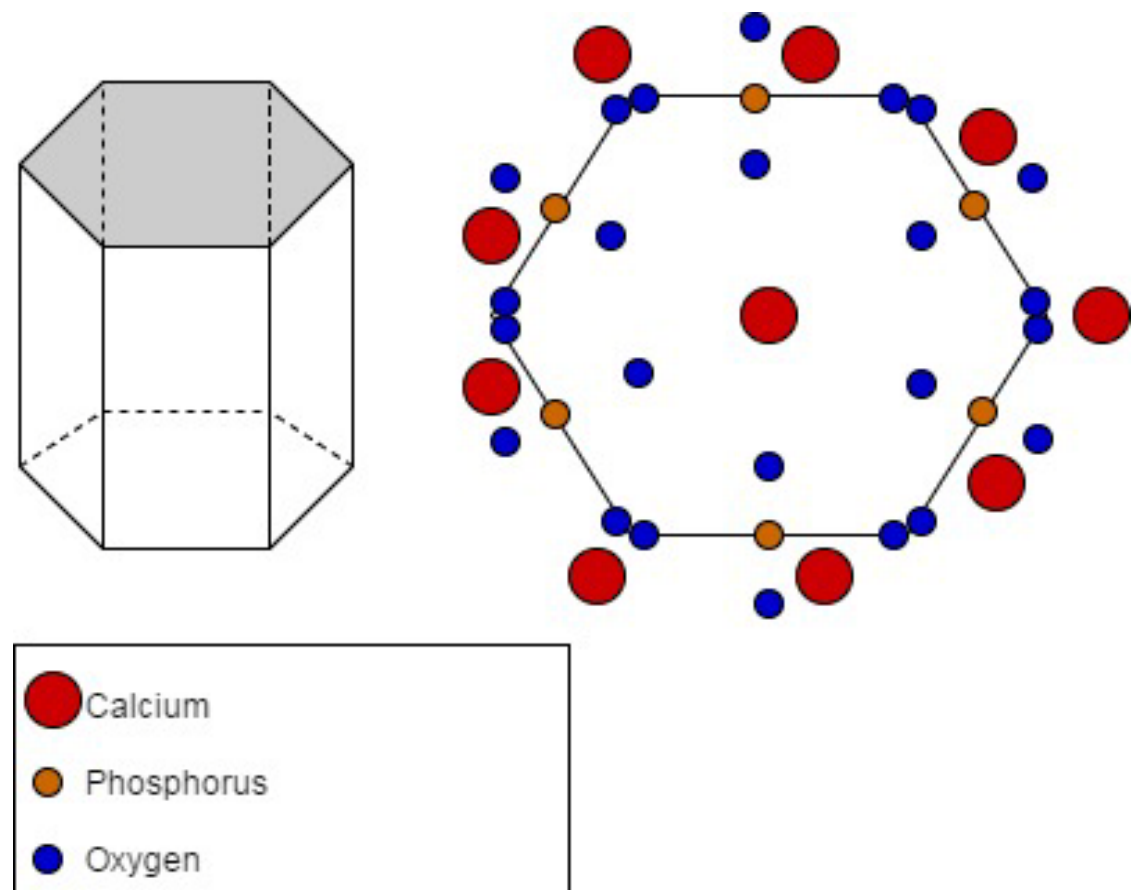

Figure 6: Crystal structure of HAp that composed of calcium $(C)$, phosphorus $(P)$ and Oxygen $(O)$ atoms

The crystal shaped structure of the sample played a crucial role that influenced the $N_{2}$ adsorption which then was reflected on the pore characteristics.
The crystal pore structure of the HAp demonstrated a long hexagonal rod-like shape. 
The pore size and pore volume of the samples were acquired from the Barrett-Joyner-Helenda (BJH) method while the surface area was determined by the Brunauer-Emmett-Teller (BET) method. Figure 7 presents the pore parameters and BET surface area of the samples. The pore volume of raw bone (RB), extracted hydroxyapatite nanoparticles (HAp-1) and standard hydroxyapatite (HAp-2) were $0.0017,0.1179$ and $0.0101 \mathrm{~cm}^{3} / \mathrm{g}$, respectively.HAp-1 demonstrated higher pore volume compared to the RB and HAp. The specific surface area of RB, HAp-1 and HAp-2 were
2.27, 22.07 and $1.90 \mathrm{~m}^{2} / \mathrm{g}$, respectively.HAp-1 exhibited a higher surface area compared to RB and HAp-2.This phenomenon might be due to the formation of the nanostructure of HAp that contributed to the greater size of the specific surface area. This phenomenon correlated with the different size of particles which influences the properties of the HAp particle. The formation of HAp-1 nanostructure has dramatically altered the performance and features of the particle. The pore size of RB, HAp-1 and HAp-2 were $0.0129,0.0235$ and $0.0489 \mu \mathrm{m}$, respectively.

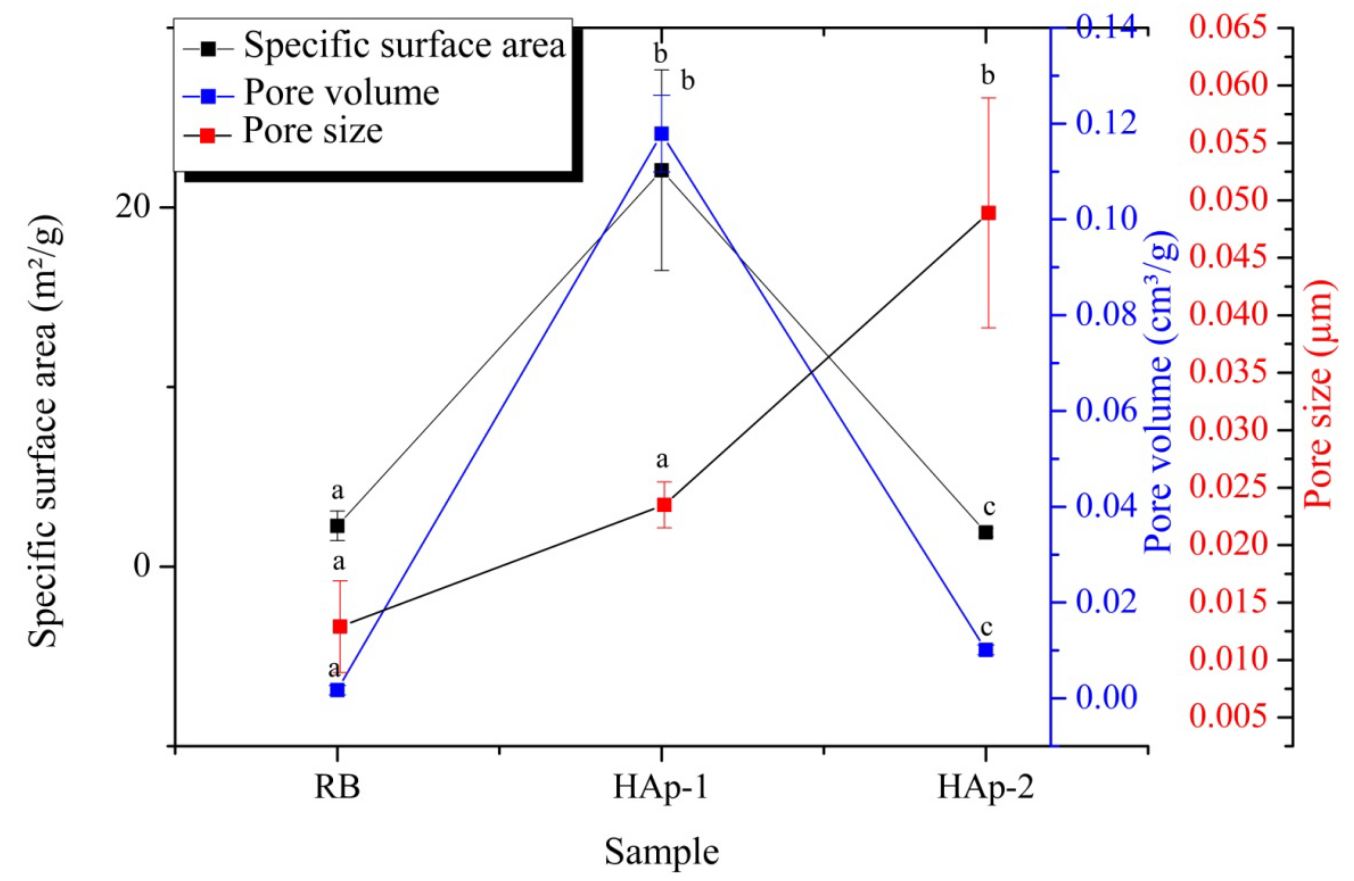

Figure 7: Comparison of pore parameters and BET surface area of RB, HAp-1 and HAp-2

RB: Raw bone; HAp-1: Extracted hydroxyapatite nanoparticles;

\section{HAp-2: Standard hydroxyapatite}

All of the samples showed a predominantly mesoporous pore structure. The pore structure of a sample can be classified into micropore $(0.1$ to $1 \mathrm{~nm})$, mesopore (1 to $10 \mathrm{~nm}$ ) and macropore (10 to 1000 $\mu \mathrm{m})$. The specific surface area and pore volume of HAp1 were increased with the decreasing of the particle size.This phenomenon may be due to the smaller particle size that contributed to the greater exposure of the atoms which led to the abundant formation of reactive sites (Cui et al., 2016). The present finding is further supported by Zanotto et al., (2012) who found that the specific surface area of $\mathrm{HAp}$ is inversely proportional with the temperature and particle size. This finding is also in good alignment with those previously stated in Section 3.1 which demonstrated the nanoparticle size of HAp-1. Therefore, it is indicated that the size of the particle was inversely proportional to the specific surface area. Figure 8 shows a possible mechanism of the nitrogen $\left(\mathrm{N}_{2}\right)$ adsorption through the pore structure of the HAp crystal. 

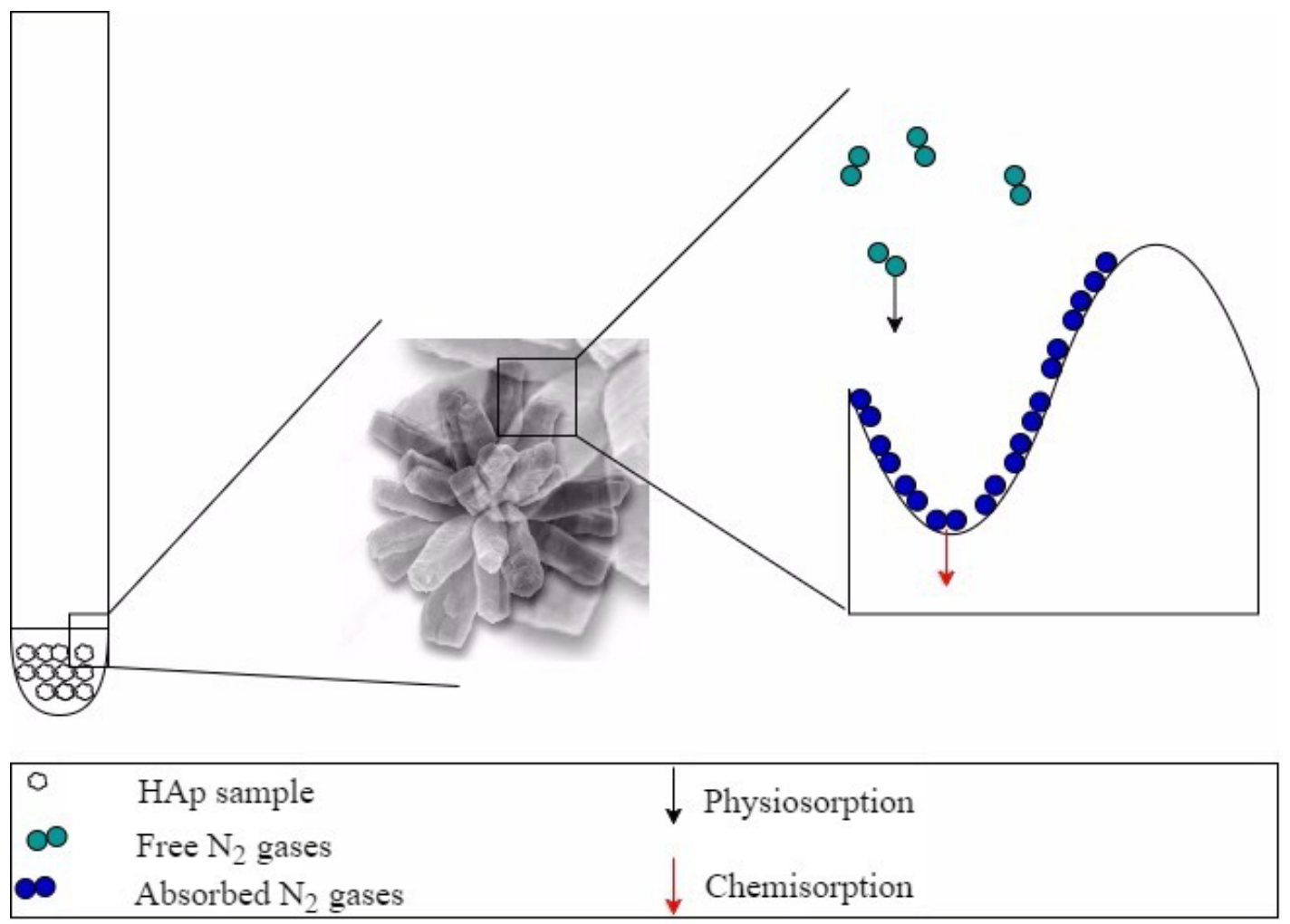

Figure 8: Mechanism of nitrogen $\left(\mathrm{N}_{2}\right)$ gases sorption into the pore of HAp crystal through physiosorption and chemisorption

HAp: Hydroxyapatite; $\mathrm{N}_{2}$ : Nitrogen

The adsorption of gas molecules into the pore structure of HAp can be illustrated by the binding of the free $\mathrm{N}_{2}$ gas molecules into the pore surface of the HAp through physiosorption and chemisorption mechanisms. The absorbed gas molecules formed a monolayer at the first phase before forming a multilayer of the molecule. The physiosorption occurred at this stage due to the van der Waals attraction which is usually used for the pore parameters determination. The adsorption of the gas is generally dependent on the time, pressure, surface energy distribution and surface area. The gas may undergo chemisorption at a later phase due to the chemical bonding attraction which may be contributed by the activation energy.

\section{Conclusion}

The extracted nano-hydroxyapatite (nano-HAp) extracted from spotted sardinella (Amblygaster sirm) bone can be an alternative to the synthetic hydroxyapatite (HAp). This is because theHAp extracted from Amblygaster sirm bonedemonstrated high yield $(55.06 \%)$ at optimum calcination temperature $\left(700^{\circ} \mathrm{C}\right)$. Morphological structure of nano-HAp was observed to exhibit a spherical-like shape with particle size distribution range from 95 to $100 \mathrm{~nm}$. The size of nano-HAp is an important factor that can influence its properties, performance and compatibility to be used in certain application. The particle size of nano-HAp can also be adjusted by the calcination temperature and effects of milling. Calcium to phosphorus $(\mathrm{Ca} / \mathrm{P})$ ratio of nano-HAp was close to theoretical stoichiometricand standard HAp ratio. It also demonstrated higher specific surface area and pore volume which were $22.07 \mathrm{~m}^{2} / \mathrm{g}$ and $0.1179 \mathrm{~cm}^{3} / \mathrm{g}$, respectively. The increased on the specific surface area of nano-HAp has potential for efficient absorption mechanism and interchange of ion. The properties of nano-HAp are the important features to be used for removal of unwanted ions, bacteria and acidic medium in the teeth. This biological source of HAp is more preferable due to less toxic, low-cost, incomplicated and time-saving for the prodction process. These findings suggested that the extracted nano-HAp can be potentially commerciallized andused for various purposes ofapplications.

\section{AcKnowledgments}

The authors would like to acknowledge the Talent and Publication Enhancement Research Grant (TAPE-RG) [Vot. No 55273] for funding the research. The authors would also like to extend the acknowledgment to the Faculty of Fisheries and Food Science, Faculty of Ocean Engineering Technology and Informatics, Institute Oceanography and Environment and Centre of Research and Field Work Services of 
Universiti Malaysia Terengganu (UMT) for providing access to facilities and materials for completing the experiments.

\section{Abbreviations}

Al: Aluminium; ANOVA: Analysis of Variance; BET: Bruaauer-Emmett-Teller; BJH: Barrett-JoynerHalenda; Ca: Calcium; Cl:Chlorine; EDS; Energy Disperse Spectroscopy; HAp: Hydroxyapatite; HAp-1: Extracted nano-hydroxyapatite; HAp-2: Standard hydroxyapatite; K: Potassium; $\mathrm{Na}$ : Sodium; $\mathrm{N}_{2}$ : Nitrogen; O: Oxygen; P: Phosphorus; RB: Raw bone; SEM: Scanning ElectronMicroscopy; Si: Silicon; TGA: Thermogravimetric Analysis.

\section{Authors' contributions}

$\mathrm{MRH}, \mathrm{NFM}$ and MSMG designed the experiments. $\mathrm{MRH}$ performed theexperiments. $\mathrm{MRH}$ analyzed the data and drafted the manuscript. $M R H$, NFM and MSMG helped to draft the manuscript. All authors read and approved the finalmanuscript.

\section{References Références Referencias}

1. Adak, M. D., and Purohit, K. M. (2011). Synthesis of Nano-Crystalline Hydroxyapatite from Dead Snail Shells for Biological Implantation. Trends in Biomaterials and Artificial Organs, 25(3), 101-106.

2. Agrawal, K., Singh, G., Puri, D., and Prakash, S. (2011). Synthesis and Characterization of Hydroxyapatite Powder by Sol-Gel Method for Biomedical Application. Journal of Minerals and Materials Characterization and Engineering, 10(8), 727-734.

3. Ajami, S., Pakshir, H. R., and Babanouri, N. (2016). Impact of Nanohydroxyapatiteon Enamel Surface Roughness and Color Change After Orthodontic Debonding. Progress in Orthodontics, 17(1), 1-12.

4. Bahrololoom, M. E., Javidi, M., Javadpour, S., and $\mathrm{Ma}$, J. (2009). Characterisation of natural hydroxyapatite extracted from bovine cortical bone ash. Journal of Ceramic Processing Research, 10(2), 129-138.

5. Barakat, N. A. M., Khil, M. S., Omran, A. M., Sheikh, F. A., and Kim, H. Y. (2009). Extraction of Pure Natural Hydroxyapatite from the Bovine Bones Bio Waste by Three Different Methods. Journal of Materials Processing Technology, 209(7), 34083415.

6. Boutinguiza, M., Pou, J., Comesaña, R., Lusquiños, F., de Carlos, A., and León, B. (2012). Materials Science and Engineering, 32, 478-486.

7. Chow, L. C., and Hockey, B. (2004). Prepared by a Spray Drying Technique. Journal of Research of the National Institute of Standards and Technology, 109(6), 543-551.

8. Christian, P., Kammer, F.V., Baalousha, M. and Hofmann, T. (2008). Nanoparticles: Structure,
Properties, Preparation and Behaviour in Environmental Media. Ecotoxicology, 17(5), 326-343.

9. Ciobanu, C. S., Andronescu, E., and Predoi, D. (2011). BET and XRD Studies on the Hydroxyapatite and Europium Doped Hydroxyapatite. Journal of Optoelectronics and Advanced Materials, 13(7), 821-824.

10. Coatchup, M. J., Blunn, G. W., Flynn, N., Williams, C., and Thomas, N. P. (1999). A Comparison of Bone Remodelling around Hydroxyapatite-Coated, Porous-Coated and Grit-Blasted Hip Replacements Retrieved at Post-Mortem. The Journal of Bone and Joint Surgery (Br), 2000 (82-B), 118-123.

11. Coelho, T. M., Nogueira, E. S., Weinand, W. R., Lima, W. M, Steimacher, A., Medina, A. N., Baesso, M. L., and Bento, A. C. (2007). Thermal properties of natural nanostructured hydroxyapatite extracted from fish bone waste. Journal of Applied Physics, 101(8), 1-6.

12. Corrêa, T. H. A., and Holanda, J. N. F. (2019). Fish Bone as a Source of Raw Material for Synthesis of Calcium Phosphate. Materials Research, 22(1), 1-5.

13. Cui, X., Liang, T., Liu, C., Yuan, Y., and Qian, J. (2016). Correlation of Particle Properties with Cytotoxicity and Cellular Uptake of Hydroxyapatite Nanoparticles in Human Gastric Cancer Cells. Material Science Engineering C,67, 453-460.

14. Dorozhkin, S. (2013). Self-Setting Calcium Orthophosphate Formulations. Journal of Functional Biomaterials,4(4), 209-311.

15. Fernando, M. S., De Silva, R. M., and De Silva, K. M. N. (2015). Synthesis, Characterization, and Application of Nano Hydroxyapatite and Nanocomposite of Hydroxyapatite with Granular Activated Carbon for the Removal of $\mathrm{Pb} 2+$ from Aqueous Solutions. Applied Surface Science,351, 95-103.

16. Gentile, P., Wilcock, C. J., Miller, C. A., Moorehead, R., and Hatton, P. V. (2015). Process Optimisation to Control the Physico-chemical Characteristics of Biomimetic Nanoscale Hydroxyapatites Prepared using Wet Chemical Precipitation. Materials,8(5), 2297-2310.

17. Gergely, G., Wéber, F., Lukács, I., Tóth, A. L., Horváth, Z. E., Mihály, J., and Balázsi, C. (2010). Preparation and Characterization of Hydroxyapatite from Eggshell. Ceramics International, 36(2), 803806.

18. Giraldo-Betancur, A. L., Espinosa-Arbelaez, D. G., Del Real-López, A., Millan-Malo, B. M., RiveraMuñoz, E. M., Gutierrez-Cortez, E., and RodriguezGarcía, M. E. (2013). Comparison of Physicochemical Properties of Bio and Commercial Hydroxyapatite. Current Applied Physics, 13(7), 1383-1390.

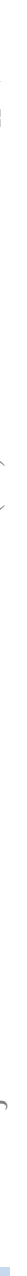


19. Guo, X., Yan, H., Zhao, S., Li, Z., Li, Y., and Liang, X. (2013). Effect of Calcining Temperature on Particle Size of Hydroxyapatite Synthesized by Solid-state Reaction at Room Temperature. Advanced Powder Technology, 24(6), 1034-1038.

20. Hu, J., Russell, J. J., Ben-Nissan, B., and Vago, R. (2001). Production and Analysis of Hydroxyapatite from Australian Corals via Hydrothermal Process. Journal of Materials Science Letters, 20(1), 85-87.

21. Huang, Y-C., and Chu, H-W. (2013). Using Hydroxyapatite from Fish Scales to Prepare Chitosan/Gelatin/Hydroxyapatite Membrane: Exploring Potential for Bone Tissue Engineering. Journal of Marine Science and Technology, 21 (6), 716-722.

22. IUPAC, "Manual of Symbols and Terminology, Appendix 2, Part 1, Colloid and Surface Chemistry," Pure andApplied Chemistry, 31(4), 578-638.

23. Jahan, A.S., Mollah, M. Y. A., Ahmed, S., and Abu Bin Hasan Susan, M. (2017). Nano-Hydroxyapatite Prepared from Eggshell-Derived Calcium-Precursor using Reverse Microemulsions as Nanoreactor. Materials Today: Proceedings, 4(4), 5497-5506.

24. Kamieniak, J., Bernalte, E., Foster, C., Doyle, A., Kelly, P., and Banks, C. (2016). High Yield Synthesis of Hydroxyapatite (HAP) and Palladium Doped HAP via a Wet Chemical Synthetic Route. Catalysts, 6(8), 119.

25. Khandelwal, H., and Prakash, S. (2016). Synthesis and Characterization of Hydroxyapatite Powder by Eggshell. Journal of Minerals and Materials Characterization and Engineering., 4(March), 119-126.

26. Khoo, W., Nor, F.M., Ardhyananta, H., and Kurniawan, D. (2015). Preparation of Natural Hydroxyapatite from Bovine Femur Bones Using Calcination at Various Temperatures. Second International Materials, Industrial, and Manufacturing Engineering Conference, 2( 2015 ), 196 - 201.

27. Michael, F. M., Khalid, M., Ratnam, C. T., Chee, C. Y., Rashmi, W., andHoque, M. E. (2016). Sonosynthesis of nanohydroxyapatite: Effects of process parameters. Ceramics International, 42, 6263-6272.

28. Mondal, S., Mondal, B., Dey, A., and Mukhopadhyay, S. S. (2012). Studies on Processing and Characterization of Hydroxyapatite Biomaterials from Different Bio Wastes. Journal of Minerals and Materials Characterization and Engineering, 11(1), 55-67.

29. Muhammad, N., Gao, Y., Iqbal, F., Ahmad, P., and Ge, R. (2016). Extraction of Biocompatible Hydroxyapatite from Fish Scales using Nvel Approach of Ionic Liquid Pretreatment, Separation and Purification Technology, 161 (2016), 129-135.

30. Nazari, M., Ghasemi, N., Maddah, H., and Motlagh, M. M. (2014). Synthesis and Characterization of Maghemite Nanopowders by Chemical Precipitation
Method. Journal of Nanostructure in Chemistry,4(2), 99-104.

31. Ofudje, E. A., Rajendran, A., Adeogun, A. I., Idowu, M. A., Kareem, S. O., and Pattanayak, D. K. (2018). Synthesis of organic derived hydroxyapatite scaffold from pig bone waste for tissue engineering applications. Advanced Powder Technology, 29(1), 1-8.

32. Ozawa, M., Hattori, M., and Satake, K. (2007). Waste Management and Application of Fish Bone Hydroxyapatite for Waste Water Treatment. Proceedings of International Symposium on EcoTopia Science 2007, 7, 957-958.

33. Pal, A., Paul, S., Roy, A., Krishna, V., Das, M., and Sinha, A. (2017). Synthesis of Hydroxyapatite from Lates calcariferfish bone for biomedical applications. Materials Letters, 1-4.

34. Poinern, G.E.J., Brundavanam, S., Tripathy, S.K., Suar, M., and Fawcett, D. (2016). Kinetic and Adsorption Behaviour of Aqueous Cadmium Using a $30 \mathrm{~nm}$ Hydroxyapatite Based Powder Synthesized Via a Combined Ultrasound and Microwave Based Technique. Physical Chemistry, 6(1), 11-22.

35. Prasad, A., Mohan Bhasney, S., Sankar, M. R., and Katiyar, V. (2017). Fish Scale Derived Hydroxyapatite reinforced Poly (Lactic acid) Polymeric Bio-films: Possibilities for Sealing/locking the Internal Fixation Devices. Materials Today: Proceedings, 4(2), 1340-1349.

36. Ruphuy, G., Saralegi, A., Lopes, J. C., Dias, M. M., and Barreiro, M. F. (2016). Spray Drying as a Viable Process to Produce Nano-hydroxyapatite/chitosan (n-HAp/CS) Hybrid Microparticles Mimicking Bone Composition. Advanced Powder Technology, 27(2), 575-583.

37. Rivera, E. M., Araiza, M., Brostow, W., Castaño, V. M., Díaz-Estrada, J. R., Hernández, R., and Rodríguez, J. R. (1999). Synthesis of Hydroxyapatite from Eggshells. Materials Letters, 41(3), 128-134.

38. Sivaperumal, V. R., and Mani, R. (2017). Materials Characterization Direct hydrothermal synthesis of hydroxyapatite/alumina nanocomposite, 134(2017), 416-421.

39. Sunil, B. R., and Jagannatham, M. (2016). Producing Hydroxyapatite from Fish Bones by Heat Treatment. Materials Letters, 185, 411-414.

40. Sobczak-kupiec A., Olender, E., Malina, D., and Tyliszczak, B. (2018). Effect of calcination parameters on behavior of bone hydroxyapatite in artificial saliva and its biosafety. Materials Chemistry and Physics, 206, 158-165.

41. Sofronia, A. M., Baies, R., Anghel, E. M., Marinescu, C. A., and Tanasescu, S. (2014). Thermal and structural characterization of synthetic and natural nanocrystalline hydroxyapatite. Materials Science \& Engineering C, 43, 153-163. 
42. Sun, R. X., Lv, Y., Niu, Y. R., Zhao, X. H., Cao, D. S., Tang, J., and Chen, K. Z. (2017). Physicochemical and Biological Properties of Bovine-derived Porous Hydroxyapatite/collagen Composite and its Hydroxyapatite Powders. Ceramics International, 43(18), 16792-16798.

43. Sutapa I.W., Romawaty and Bandjar, A. (2016). Synthesis $\mathrm{Ca}^{3}\left(\mathrm{PO}^{4}\right)^{2}$ from Tuna Fish Bone and Potential as a Catalyst in the Transesterification Reaction for Biodiesel Production I. Journal of Chemical and Pharmaceutical Research,8(8), 596604.

44. Tsai, S. W., Hsu, F. Y., and Chen, P. L. (2008). Beads of Collagen-Nanohydroxyapatite Composites prepared by a Biomimetic Process and the Effects of Their Surface Texture on Cellular Behavior in MG63 Osteoblast-like Cells. Acta Biomaterialia, 4(5), 1332-1341.

45. Venkatesan, J., Lowe, B., Manivasagan, P., Kang, K. H., Chalisserry, E. P., Anil, S., and Kim, S. K. (2015). Isolation and Characterization of Nanohydroxyapatite from Salmon Fish Bone. Materials, 8(8), 5426-5439.

46. Zanotto, A., Saladino, M. L., Martino, D. C., and Caponetti, E. (2012). Influence of Temperature on Calcium Hydroxyapatite Nanopowders.Advances in Nanoparticles, 1(3),21-28.

47. Zhou, H., and Lee, J. (2011). Nanoscale Hydroxyapatite Particles for Bone Tissue Engineering. Acta Biomaterialia,7(7), 2769-2781. 